\title{
Food Preparation Practices for Infants Aged From 7 to 13 Months
}

\author{
Michaila Czarnik, $\mathrm{MPH}^{1,2}$; Heather C. Hamner, $\mathrm{PhD}, \mathrm{MS}, \mathrm{MPH}^{1}$; \\ Latetia V. Moore, PhD, $\mathrm{MSPH}^{1}$
}

\begin{abstract}
Objective: To examine infant food preparation practices at age 7, 9, 11, and 13 months overall and by sociodemographic characteristics.

Design: Data from a longitudinal study from the US Department of Agriculture's Special Supplemental Nutrition Program for Women, Infants, and Children (WIC) Infant and Toddler Feeding Practices Study-2 (ITFPS-2) were used.

Participants: A sample of 1,904 infants (970 males and 934 females) enrolled in WIC who had been introduced to solid foods and were consuming food prepared at home.

Main Outcome Measures: Food preparation practices included pureeing, mashing, chopping/dicing, and prechewing. Estimates were provided overall and by sociodemographics.

Analysis: Prevalence estimates were calculated for each survey month overall and by sociodemographics. Chi-square tests for independence were used to test for differences.

Results: Food preparation practices changed as infants aged. Pureeing and mashing were common in month 7 (57.8\% and 59.6\%, respectively), but chopping/dicing were the most prevalent by month 13 (85.4\%). Food preparation practices did not vary by education status, but statistical differences were consistently observed by race and ethnicity and inconsistently observed by maternal age at birth.

Conclusions and Implications: Exposing children to a range of food textures at an appropriate age is important for developmental progress. Continued culturally relevant efforts by WIC educators and health care providers can emphasize the importance of early experiences with food textures.

Key Words: feeding methods, feeding behavior, food assistance, weaning, infant food (J Nutr Educ Behav. 2022;54:28-35.)
\end{abstract}

Accepted August 15, 2021. Published online September 28, 2021.

\section{INTRODUCTION}

Exposing children to a range of food textures at an appropriate age and stage is not only important for developmental progress, but it may also be important for later dietary behaviors. ${ }^{1}$ Children are more likely to accept a range of food textures if exposed when the brain is particularly receptive to the effects of the experience, typically during the early complementary feeding phase or ages 6-12 months., ${ }^{2,3}$ After this time, different textures can still be introduced and even accepted, but it may take more effort. ${ }^{2,3}$

Specific feeding guidelines on when to introduce and how to prepare food, including exposures to different food textures, for young children are available. ${ }^{4,5}$ For example, the US Department of Agriculture's Special

\footnotetext{
${ }^{1}$ Division of Nutrition, Physical Activity, and Obesity, National Center for Chronic Disease Prevention and Health Promotion, Centers for Disease Control and Prevention, Atlanta, Georgia

${ }^{2}$ Oak Ridge Institute for Science and Education, Oak Ridge, Tennessee

Conflict of Interest Disclosure: The authors have not stated any conflicts of interest.

Address for correspondence: Heather C. Hamner, PhD, MS, MPH, National Center for Chronic Disease Prevention and Health Promotion, Centers for Disease Control and Prevention, 4770 Buford Hwy NE, Mail-Stop S107-5, Atlanta, GA 30341-3717; E-mail: hfc2@cdc.gov

Published by Elsevier Inc. on behalf of Society for Nutrition Education and Behavior. This is an open access article under the CC BY-NC-ND license (http://creativecommons.org/ licenses/by-nc-nd/4.0/)

https://doi.org/10.1016/j.jneb.2021.08.006
}

Supplemental Nutrition Program for Women, Infants, and Children (WIC) Program provides detailed feeding guidelines for its almost 2 million enrolled infants, along with supplemental food, nutrition education, and screening and referrals for other health care services for eligible infants, children aged $\leq 5$ years, and pregnant and postpartum women from low income areas. These feeding guidelines support the development of chewing, fine motor, and self-feeding skills while accounting for general progression of infant oral development, number and type of teeth, and safety from choking. ${ }^{4}$ Advice on exposing children to a variety of food textures is also described. For example, beginning at ages $6-8$ months, plain fruits, cooked vegetables, and proteinrich foods can be pureed, strained, or mashed, followed by ground, finely chopped, or diced food at age 8-12 months. ${ }^{4}$ The WIC guidelines vary by food groups and age and are 
consistent with guidance for the general population from the American Academy of Pediatrics (AAP). ${ }^{5}$ A recent report by the National Academies of Science, Engineering, and Medicine conducted a scoping review of the feeding recommendations for infants and young children, including both what and how to feed. ${ }^{6}$ Although the majority of recommendations identified focused on what to feed, a third of identified recommendations described topics related to how to feed, including food consistency and texture. ${ }^{6}$ Recommendations for this topic were consistent and noted that foods and textures should be developmentally appropriate for an individual child and should change as the child ages. ${ }^{6}$

Despite the benefits of introducing a range of textures and consistent, available guidance on how to prepare food for infants at appropriate ages, limited information is available on food preparation practices. With more than half (56\%) of all infants in the US eligible for WIC in $2017,{ }^{7}$ a better understanding of how foods are prepared by WIC caregivers, including the exposure to a range of food textures during a key period, could provide insights into early dietary behaviors and patterns. It may also inform infant feeding education provided by WIC educators and health care providers. Therefore, the purpose of this cross-sectional analysis was to examine infant food preparation practices at ages $7,9,11$, and 13 months overall and by sociodemographic characteristics among the WIC population.

\section{METHODS}

\section{Data Source}

Data were used from a longitudinal study, the WIC Infant and Toddler Feeding Practices Study-2 (ITFPS-2), that follows children enrolled in WIC through age 6 years to assess dietary and feeding practices, WIC services related to feeding support, and health outcomes. ${ }^{8}$ The WIC ITFPS-2 was conducted using a twostage stratified sampling approach to enroll participants. Within the first sampling stage, WIC sites were selected using a probability proportional sampling design. Special Supplemental Nutrition Program for Women, Infants, and Children sites were eligible if they were projected to enroll $\geq 30$ participants per month. Eighty WIC sites were selected across 27 states, representing $37 \%$ of WIC sites and $87 \%$ of WIC participants. ${ }^{8}$

The second sampling stage identified eligible participants. All women who were enrolling in WIC for the first time or were enrolling their infant (aged $<2.5$ months) were eligible to participate. In addition, women had to be aged $\geq 16$ years and speak English or Spanish. Eligible participants were enrolled in person. Recruitment for the study occurred from July 1, 2013, through November 18, 2013.

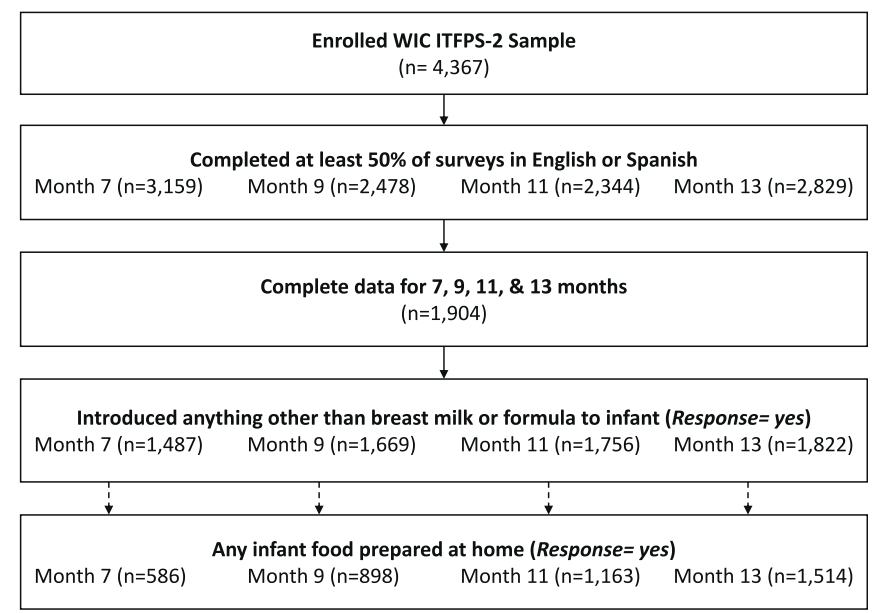

Figure 1. Flowchart of selection of analytic sample from USDA's WIC ITPFS2. Abbreviations: ITFPS-2 (Infant and Toddler Feeding Practices Study-2); USDA (United States Department of Agriculture); WIC (Special Supplemental Nutrition Program for Women, Infants, and Children).
Participants completed a series of telephone interviews throughout the study, with 8 interviews conducted in the first year (prenatal, months $1,3,5$, $7,9,11$, and 13). Of those invited to participate in the study $(n=6,775)$, 987 did not complete a screener; 1,299 were screened and ineligible, and the remaining women $(n=4,489)$ were screened and eligible to enroll. ${ }^{8}$ Of those screened and eligible, 4,367 enrolled. The current analysis uses data from months $7,9,11$, and 13; response rates among those enrolled varied by month, $72.3 \%, 56.7 \%$, $53.7 \%$, and $64.8 \%$, respectively. ${ }^{8}$

Written consent from participants was obtained during study screening and enrollment. Participants received incentives for enrolling and completing each interview. This study was a registered study at clinicaltrials.gov (NCT02031978).

\section{Analytic Population}

Analyses were limited to those who had complete data at all 4 survey timepoints (months 7, 9, 11, and 13) $(n=1,904)$ to ensure appropriate comparisons within each cross-sectional timepoint. A flow chart of the analytic population is provided (Figure 1).

\section{Introduction to Solids}

At every interview, caregivers were asked, "Has [child] been given anything to eat or drink besides formula or breast milk?" Response options were yes or no. Only caregivers who responded yes in months $7,9,11$, or 13 were considered for further analysis (month $7[\mathrm{n}=1,487]$, month 9 $[\mathrm{n}=1,669]$, month 11 [ $\mathrm{n}=1,756]$, month $13[\mathrm{n}=1,822])$. This question was used to calculate the prevalence of infants consuming anything other than breast milk or formula at each survey month and was used as a proxy for introduction to solids because of the infants' age at survey time points (hereafter referred to as introduced to solids). For example, infants who have been introduced to solids before or at 7 months are included in the denominator for months 9, 11, and 13 . 


\section{Infant Food Prepared at Home}

Caregivers who responded yes to solids were eligible to answer questions about types of infant food prepared at home. Caregivers were asked whether 5 different food categories were store-bought baby food (ie, foods sold in a jar or a container sold especially for babies) over the past 7 days ([1] fruit and vegetable juice, [2] fruit, [3] vegetables, [4] meat such as beef or chicken, and [5] combination dinners). Response options included all, mostly, some, no storebought baby food, or not fed this food in the past 7 days. Respondents reporting no, some, or mostly storebought baby food were asked about infant food preparation practices at home.

\section{Food Preparation Practices}

Five different food preparation practices were assessed with a yes/no response for each: (1) puree, such as in a blender or food processor; (2) mash, such as with a fork or spoon; (3) chop or dice; (4) chew foods yourself before giving to their child; and (5) other. Respondents that reported don't know or refused were recategorized as no (a total of 4 responses of don't know or refused for mashed at months 7,9 , or 11 ; a total of 11 responses of don't know or refused for pureed, mashed, chop/dice, or prechew at month 13). A sensitivity analysis was conducted, and excluding don't know or refused from no responses yielded similar findings. Analyses of food preparation practices were restricted to puree, mash, chop/dice, and prechew.

\section{Covariates}

Covariates include infant's sex (male or female), maternal age ( $\leq 25$ years or $\geq 26$ years), maternal educational attainment $(\leq$ high school or $>$ high school), and mother's race and ethnicity (non-Hispanic Black, non-Hispanic White, non-Hispanic other race, or Hispanic). For analyses stratified by race and ethnicity, individuals categorized as non-Hispanic other race were not displayed because of limited sample size. Race and ethnicity were self-reported; participants indicated their ethnicity (Hispanic or Latino, or Not Hispanic or Latino) and race via an open-ended question with a select all that apply option (American Indian or Alaskan Native, Asian, Black or African American, Native Hawaiian or Other Pacific Islander, White, other (specify)]. In the publicly available data set, race categories were provided as Black or African American, White, and all other; ethnicity categories were provided as: Hispanic or Latino, or Not Hispanic or Latino. Race and ethnicity were combined into 1 variable for this analysis.

\section{Statistical Analysis}

Prevalence estimates for introduction to solids, foods prepared at home, and food preparation practices were calculated for each survey month overall and by maternal race and ethnicity, maternal age at birth, and education level. Chi-square tests for independence were used to test for differences between demographic characteristics and food preparation practices within each month among those fed any food prepared at home. Bonferroni corrected $P$ values < 0.0125 were considered statistically significant. A previously developed weight to account for the differential selection and nonresponse was unavailable for individuals who participated in months 7, 9, 11, and 13 . Therefore, weights for each survey month (ie, months $7,9,11$, or 13) were used in the cross-sectional analysis. A sensitivity analysis was conducted comparing monthly weighted estimates to non-weighted estimates, and findings did not change, and estimates were not statistically different from one another. Therefore, analyses at each survey month were weighted using the corresponding month weight to represent the WIC population enrolled in WIC sites with $\geq 30$ participants/month and adjust for the differential probability of selection and nonresponse. For demographic characteristics of the total analytic population, estimates were not weighted because appropriate survey weights for the combination of surveys months presented were not available. The software SAScallable SUDAAN was used to account for the complex survey design (SUDAAN release 11.0.3, RTI International, 2018). The Centers for Disease Control and Prevention determined that this secondary analysis of de-identified data was not human subjects research and did not require Institutional Review Board review.

\section{RESULTS}

Of the 1,904 caregivers in the analytic sample, $39.8 \%$ identified as Hispanic, $31.9 \%$ identifying as non-Hispanic White, and $22.6 \%$ identifying as nonHispanic Black (unweighted; data not presented). Half were aged 26 years or older $(50.0 \%)$, and most caregivers had less than a high school education (61.1\%) (unweighted; data not presented).

At 7 months, $78.1 \%$ of infants had been introduced to foods or beverages other than infant formula or breast milk, and this percentage was higher at each succeeding month at $87.9 \%, 92.4 \%$, and $96.0 \%$ at 9,11 , and 13 months, respectively (Table). This pattern was consistent across sociodemographic groups. However, there were differences in the proportion of infants introduced to solids by sociodemographic factors within each month (Table). For example, at month $7,80.1 \%$ of non-Hispanic Black caregivers, $85.1 \%$ of non-Hispanic White caregivers, and $73.4 \%$ of Hispanic caregivers had introduced solids $(P<0.01)$.

Among infants introduced to solids by 7 months, $42.5 \%$ had at least 1 infant food category prepared for them at home. The percentage of at least 1 food category prepared at home was higher at each succeeding month $(55.0 \%$ in month $9,68.7 \%$ in month 11 , and $83.7 \%$ in month 13 ) (data not presented). Again, some differences were noted in the proportion of infants who had at least 1 infant food category prepared for them at home within each month by select sociodemographic factors. For example, at month $11,64.5 \%$ of caregivers aged $\leq 25$ years were serving infant food prepared at home, compared with $72.9 \%$ of caregivers aged $>26$ years $(P<0.01)$.

Among infants who had been introduced to solids and had at least 
Table. The proportion of infants who had been introduced to solids and had any food prepared at home by sociodemographic characteristics at months 7 9, 11, and 13, USDA's WIC Infant and Toddler Feeding Practices Study-2

\begin{tabular}{|c|c|c|c|c|c|c|c|c|}
\hline \multirow[b]{2}{*}{ Characteristics } & \multicolumn{4}{|c|}{ Introduced to Solids ${ }^{a}$} & \multicolumn{4}{|c|}{ Any Food Prepared At Home ${ }^{b}$} \\
\hline & $7 \mathrm{mo}^{\mathrm{c}, \mathrm{d}}$ & $9 \mathrm{mo}^{\mathrm{c}, \mathrm{d}}$ & $11 \mathrm{mo}^{\mathrm{e}}$ & $13 \mathrm{mo}^{\mathrm{c}, \mathrm{d}}$ & $7 \mathrm{mo}^{\mathrm{c}, \mathrm{e}}$ & $9 \mathrm{mo}^{\mathrm{c}, \mathrm{e}}$ & $11 \mathrm{mo}^{\mathrm{c}, \mathrm{e}}$ & $13 \mathrm{mo}^{\mathrm{c}, \mathrm{d}, \mathrm{e}}$ \\
\hline $\begin{array}{l}\text { Total, \% } \\
\text { 95\% } \mathrm{Cl}^{\dagger} \\
\mathrm{n}\end{array}$ & $\begin{array}{l}78.1 \\
(75.6-80.5)\end{array}$ & $\begin{array}{l}87.9 \\
(86.0-89.8)\end{array}$ & $\begin{array}{l}92.4 \\
(90.8-94.0) \\
04\end{array}$ & $\begin{array}{l}96.0 \\
(94.8-97.2)\end{array}$ & $\begin{array}{l}42.5 \\
(38.0-47.0) \\
1,445\end{array}$ & $\begin{array}{l}55.0 \\
(50.2-59.9) \\
1,652\end{array}$ & $\begin{array}{l}68.7 \\
(65.3-72.1) \\
1,742\end{array}$ & $\begin{array}{l}83.7 \\
(81.3-86.0) \\
1,811\end{array}$ \\
\hline Maternal race and ethnici & & & & & & & & \\
\hline $\begin{array}{l}\text { Non-Hispanic Black } \\
95 \% \mathrm{Cl}^{\dagger} \\
\mathrm{n}\end{array}$ & $\begin{array}{l}80.1 \\
(75.9-84.4)\end{array}$ & $\begin{array}{l}89.0 \\
(85.4-92.5)\end{array}$ & $\begin{array}{l}93.0 \\
(89.4-96.6) \\
30\end{array}$ & $\begin{array}{l}96.1 \\
(94.0-98.1)\end{array}$ & $\begin{array}{l}32.2 \\
(25.0-39.5) \\
328\end{array}$ & $\begin{array}{l}38.9 \\
(33.4-44.3) \\
375\end{array}$ & $\begin{array}{l}56.1 \\
(50.0-62.1) \\
399\end{array}$ & $\begin{array}{l}75.9) \\
(72.2-79.6) \\
409\end{array}$ \\
\hline $\begin{array}{l}\text { Non-Hispanic White } \\
95 \% \mathrm{Cl}^{f} \\
\mathrm{n}\end{array}$ & $\begin{array}{l}85.1 \\
(82.3-87.9)\end{array}$ & $\begin{array}{l}91.2 \\
(89.0-93.5)\end{array}$ & $\begin{array}{l}95.2 \\
(93.1-97.3) \\
77\end{array}$ & $\begin{array}{l}98.2 \\
(96.7-99.8)\end{array}$ & $\begin{array}{l}26.1 \\
(20.1-32.1) \\
492\end{array}$ & $\begin{array}{l}45.4 \\
(38.8-52.0) \\
551\end{array}$ & $\begin{array}{l}62.5 \\
(56.5-68.5) \\
572\end{array}$ & $\begin{array}{l}80.6 \\
(76.1-85.0) \\
593\end{array}$ \\
\hline $\begin{array}{l}\text { Hispanic } \\
95 \% \mathrm{Cl}^{f} \\
\mathrm{n}\end{array}$ & $\begin{array}{l}73.4 \\
(70.5-76.3)\end{array}$ & $\begin{array}{l}84.8 \\
(81.8-87.7)\end{array}$ & $\begin{array}{l}90.2 \\
(87.4-92.9) \\
58\end{array}$ & $\begin{array}{l}94.4 \\
(92.5-96.2)\end{array}$ & $\begin{array}{l}57.7 \\
(52.0-63.5) \\
544\end{array}$ & $\begin{array}{l}68.2 \\
(61.5-74.8) \\
628\end{array}$ & $\begin{array}{l}79.4 \\
(74.9-83.9) \\
671\end{array}$ & $\begin{array}{l}88.3 \\
(85.1-91.5) \\
705\end{array}$ \\
\hline Maternal age at birth & & & & & & & & \\
\hline $\begin{array}{l}\leq 25 \text { years } \\
95 \% \mathrm{Cl}^{\dagger} \\
\mathrm{n}\end{array}$ & $\begin{array}{l}80.6 \\
(77.8-83.4)\end{array}$ & $\begin{array}{l}89.9 \\
(87.8-92.1)\end{array}$ & $\begin{array}{l}94.5 \\
(92.7-96.3) \\
52\end{array}$ & $\begin{array}{l}97.2 \\
(95.9-98.5)\end{array}$ & $\begin{array}{l}38.1 \\
(33.3-42.8) \\
748\end{array}$ & $\begin{array}{l}50.3 \\
(45.1-55.5) \\
847\end{array}$ & $\begin{array}{l}64.5 \\
(60.8-68.0) \\
891\end{array}$ & $\begin{array}{l}80.5 \\
(77.0-83.6) \\
920\end{array}$ \\
\hline $\begin{array}{l}\geq 26 \text { years } \\
95 \% \mathrm{Cl}^{\dagger} \\
\mathrm{n}\end{array}$ & $\begin{array}{l}75.6 \\
(72.0-79.3)\end{array}$ & $\begin{array}{l}86.0 \\
(82.8-89.2)\end{array}$ & $\begin{array}{l}90.4 \\
(87.9-93.0) \\
52\end{array}$ & $\begin{array}{l}94.8 \\
(92.7-96.9)\end{array}$ & $\begin{array}{l}47.1 \\
(41.5-52.7) \\
697\end{array}$ & $\begin{array}{l}59.8 \\
(53.9-65.3) \\
805\end{array}$ & $\begin{array}{l}72.9 \\
(68.3-77.0) \\
851\end{array}$ & $\begin{array}{l}86.9 \\
(83.6-89.6) \\
891\end{array}$ \\
\hline Maternal education status & \multicolumn{4}{|c|}{952} & & & & \\
\hline $\begin{array}{l}\text { High school or less } \\
95 \% \mathrm{Cl}^{\dagger} \\
\mathrm{n}\end{array}$ & $\begin{array}{l}75.3 \\
(71.8-78.8)\end{array}$ & $\begin{array}{l}85.3 \\
(82.7-87.9)\end{array}$ & $\begin{array}{l}91.1 \\
(89.0-93.3) \\
161\end{array}$ & $\begin{array}{l}94.9 \\
(93.4-96.4)\end{array}$ & $\begin{array}{l}43.1 \\
(36.8-49.4) \\
849\end{array}$ & $\begin{array}{l}54.6 \\
(49.5-59.7) \\
972\end{array}$ & $\begin{array}{l}67.4 \\
(63.2-71.5) \\
1,043\end{array}$ & $\begin{array}{l}81.6 \\
(78.2-84.9) \\
1,093\end{array}$ \\
\hline $\begin{array}{l}\text { More than high school } \\
95 \% \mathrm{Cl}^{\dagger} \\
\mathrm{n}\end{array}$ & $\begin{array}{l}82.9 \\
(79.4-86.3)\end{array}$ & $\begin{array}{l}92.1 \\
(89.7-94.4)\end{array}$ & $\begin{array}{l}94.4 \\
(92.2-96.7) \\
38\end{array}$ & $\begin{array}{l}97.9 \\
(96.7-99.1)\end{array}$ & $\begin{array}{l}41.4 \\
(36.3-46.5) \\
594\end{array}$ & $\begin{array}{l}55.4 \\
(49.0-61.9) \\
676\end{array}$ & $\begin{array}{l}70.6 \\
(65.5-75.6) \\
695\end{array}$ & $\begin{array}{l}87.0 \\
(84.2-89.8) \\
714\end{array}$ \\
\hline
\end{tabular}

USDA indicates US Department of Agriculture; WIC, Special Supplemental Nutrition Program for Women, Infants, and Children.

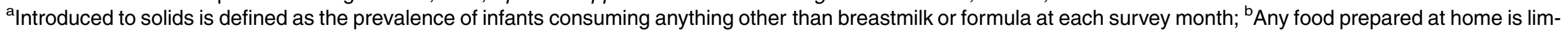
ited to those fed mostly, some, or no store-bought baby food, and excludes those not fed at least 1 of the following 5 food categories (fruit/vegetable juice; fruit; vegetables;

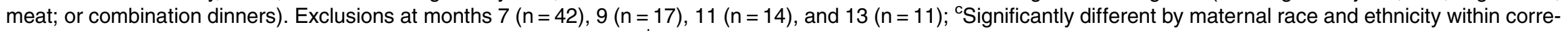

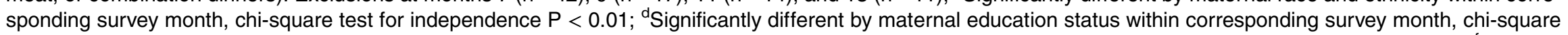

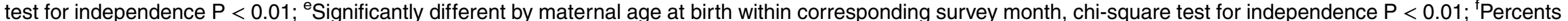

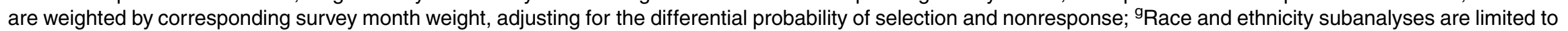
those individuals who report being either non-Hispanic Black, non-Hispanic White, or Hispanic; ' $\mathrm{D}$ oes not sum to total sample size because of missing data; introduced to solids $(n=5)$; foods prepared at home: months $7(n=2), 9(n=4), 11(n=4)$, and $13(n=4)$. 
1 infant food category prepared at home, pureeing was reported by more than half of caregivers at 7 and 9 months $(57.8 \%$ and $51.8 \%$, respectively) and then by less than half of caregivers in later months (month 11 , 46.7\%; month 13, 37.2\%) (Figure 2). In month 7, 59.6\% of caregivers reported mashing, and this percentage was higher at $82.1 \%$ in month 11. Chopping/dicing was $26.2 \%$ in month 7 and $85.4 \%$ in month 13. Approximately $11.6 \%$ to $17.7 \%$ of caregivers reported prechewing as a food preparation practice between 7 and 13 months.

Methods of preparation varied by race/ethnicity for most months and practices, but patterns were less consistent for other sociodemographic characteristics. There were statistically significant differences by food preparation practices within each month by race and ethnicity for pureeing and prechewing and in select months for mashing (months 11 and 13) and chopping/dicing (months 9, 11, and 13) (Figure 2). There were also significant differences in food preparation practices within select months by maternal age for pureeing (months 9 and 11) and prechewing (months 7 ,
9, and 13) (Supplementary Table). Regardless of sociodemographic characteristics, a similar pattern was observed with a higher proportion of pureeing in the earlier months (ie, months 7 and 9) and then a lower proportion at later months (ie, months 11 and 13). For example, in month 7, 35.8\%, 44.1\%, and $68.0 \%$ of non-Hispanic Black, non-Hispanic White, and Hispanic caregivers reported pureeing, respectively (Chisquare, $P<0.001)$. Prechewing had the most variability in each month. For example, in month 9, 21.6\% of caregivers aged $\leq 25$ years were using prechewing compared with $11.9 \%$ of caregivers aged $>26$ years (Chi-square, $P<0.01$ ) (Supplementary Table).

\section{DISCUSSION}

Among a cohort of infants enrolled in WIC, most infants had been introduced to solid foods by 7 months, with some differences noted by sociodemographic characteristics. For those who had infant food prepared at home, food preparation practices of pureeing and mashing were common at 7 and 9 months and then transitioned to chopping/dicing foods by 13 months. These practices are consistent with AAP and WIC recommendations to offer a variety of textures in thicker consistencies as children age. ${ }^{4,5}$ A smaller proportion of caregivers reported prechewing with similar proportions at 7, 9, 11, and 13 months. Prechewing, as a practice, is not encouraged in programmatic guidance from WIC. ${ }^{4}$ Systematic evidence supporting or refuting this practice is limited, and discussion continues in the scientific literature. ${ }^{9,10}$ Some studies have found this practice can increase the risk of disease transmission ${ }^{11-13}$ and developing dental caries, ${ }^{14}$ especially among caregivers infected with HIV or at risk of HIV infection. ${ }^{12}$ Other researchers have described the practice as being used historically to support the transition of breastfeeding to complementary food introduction and may have digestive, immunological, and other protective health benefits. ${ }^{15}$ A call for more research on this practice has been made to understand the risks and benefits on child health. ${ }^{16}$ The proportion of caregivers reporting different food preparation practices did not vary by

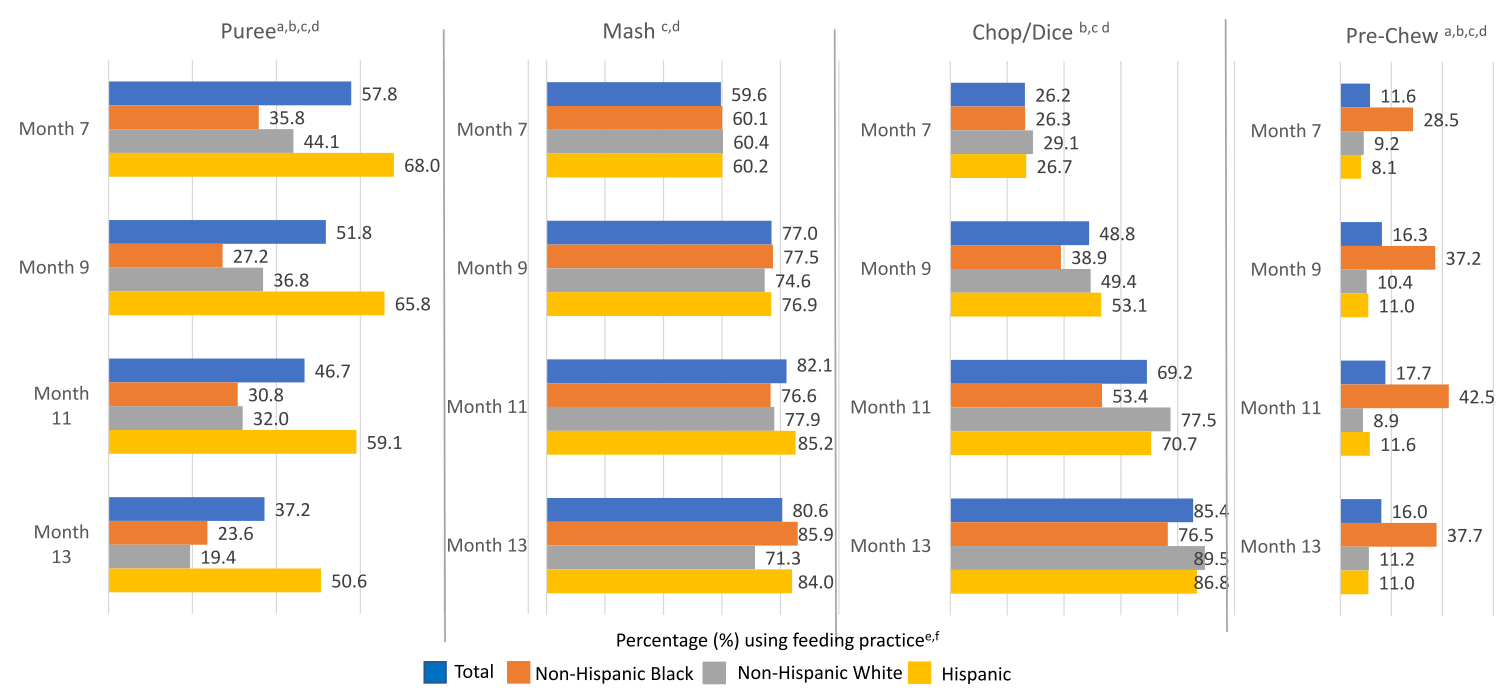

Figure 2. Proportion of feeding practices used for foods prepared at home for infants at months 7, 9, 11, and 13 by maternal race and ethnicity, WIC USDA's Infant and Toddler Feeding Practices Study-2. Abbreviations: USDA (United States Department of Agriculture); WIC (Special Supplemental Nutrition Program for Women, Infants, and Children). ${ }^{a}$ Significantly different by maternal race and ethnicity at month 7 , Chi-square test for independence $P<0.01$. ${ }^{b}$ Significantly different by maternal race and ethnicity at month 9, Chi-square test for independence $P<0.01$. ${ }^{c}$ Significantly

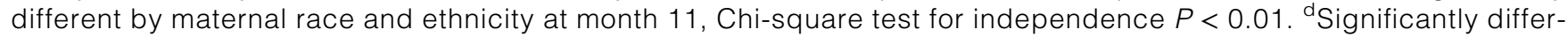

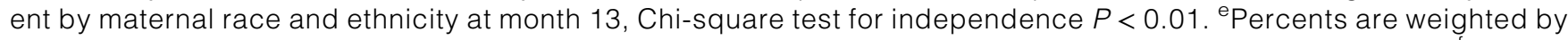
corresponding survey month weight, adjusting for the differential probability of selection and non-response. ${ }^{f}$ Percentages do not equal 100 as individuals could select more than 1 feeding practice. 
education status, but statistical differences were consistently observed by race and ethnicity and inconsistently observed by maternal age at birth. Previous studies have not assessed food preparation practices overall or by sociodemographic differences within either a low-income population or the larger US population, making our findings a unique contribution to the literature. Given the importance of early child nutrition, including the exposure to a range of food textures at an early age, findings are discussed within a broader public health context, including food acceptance, potential impacts on current and future dietary behaviors, and programmatic efforts.

Early feeding experiences, including introducing different food textures, can significantly impact food acceptance, ${ }^{3}$ dietary behaviors, ${ }^{17-19}$ dietary patterns, ${ }^{20,21}$ and health outcomes. ${ }^{22}$ Blossfield et $\mathrm{al}^{23}$ found that 12-month-old infants who had been exposed to mashed carrots previously, or a variety of textures regardless of the food item, increased acceptance of chopped foods such as carrots. ${ }^{23}$ Among a cohort of children in the United Kingdom, Northstone et $\mathrm{al}^{19}$ found that children who were not exposed to lumpy foods until after 10 months was associated with a lower likelihood of being given a variety of family foods such as meat, fish, eggs, raw fruit and raw vegetables and had an increased odds of reported feeding difficulties. Longerterm impacts of later introduction to lumpy foods ( $\geq 10$ months) were also identified, including lower scores on healthier dietary patterns at age 2 years, ${ }^{21}$ fewer portions of fruits and vegetables at age 7 years, ${ }^{1}$ and higher odds of feeding difficulties at age 7 years. ${ }^{1}$

Infants learn to eat using a variety of methods, including familiarization (repeated exposures to tastes, texture, and appearance), observation (watching or imitating others eating similar foods), associative learning (linking foods and flavors together), and categorization (grouping similar foods together). ${ }^{24}$ Repeated exposures to different food textures, such as purees, mashes, or chopped/diced foods, can be an important early step to increasing food acceptance. As described previously, there appears to be a window of opportunity during development in which a range of food textures may be more readily accepted. ${ }^{2}$ After this window closes, the ability to accept different textures is still present, but it may take more effort. ${ }^{2}$ Our findings indicated a large proportion of caregivers were preparing more textured (ie, chopped/diced) food at 11 and 13 months, which may coincide with this developmental window.

Our findings that caregivers with infants enrolled in WIC have food preparation practices that align with guidance from AAP and WIC are encouraging and support the continued promotion of the WIC feeding guidelines. ${ }^{4}$ However, not all infants and young children eligible for WIC participate in the program, ${ }^{7}$ and dietary practices have been found to differ by WIC participation status. ${ }^{25,26}$ Pediatricians, or other health care providers, could be an important conduit for families to learn about key early feeding practices, regardless of WIC participation status. The AAP has developed continuing medical education training modules that touch on a range of early child nutrition topics, including the importance of exposing young children to a variety of tastes and textures. ${ }^{27}$ In addition, educational materials from AAP targeting families and caregivers, many of which are available in both Spanish and English, provide information on how to feed young children, including food preparation methods. ${ }^{27,28}$ There are examples of other materials and programs that have been developed specifically for families and caregivers with cultural relevance and applicability, including a series of videos on early feeding developed by the Chickasaw Nation ${ }^{29}$ and a population-tested nutrition education program created in Spanish with careful consideration of traditional foods and eating customs across a range of Latino cultures. ${ }^{30}$ An opportunity exists to further these efforts, especially with the release of the US Dietary Guidelines for Americans 2020 $-2025 .^{31}$ The US Dietary Guidelines for Americans 2020-2025 provides a framework that can be used to support healthy dietary patterns, including complementary feeding practices that represent a family's preference, cultural traditions, and budgetary considerations. ${ }^{31}$ In addition to educational resources available, qualitative research has underscored the importance of understanding and celebrating diverse cultures and practices regarding early feeding. ${ }^{32}$ Scoping reviews, such as the one described by Monteith et $\mathrm{al}^{33}{ }^{33}$ on qualitative literature related to Indigenous infant feeding experiences, could provide even more insights to understanding the context of culture and traditions on infant feeding practices. Continued efforts by both WIC educators and health care providers to emphasize the importance of early experiences with different food textures, using a culturally competent approach, could help support the development of positive current dietary behaviors and practices and potentially influence later dietary behaviors for WIC and non-WIC participants alike.

Although there are available guidelines on infant and toddler feeding, including the most recent US Dietary Guidelines for Americans $2020-2025,{ }^{31}$ the evidence supporting many of the recommendations has been somewhat limited. The National Academies of Science, Engineering, and Medicine report, which identified 43 guideline documents and 18 different topic areas, highlighted that the supporting evidence for these recommendations often mapped to narrative reviews, with some linked to systematic reviews, and others to government reports and websites, or a single scientific paper. ${ }^{6}$ However, efforts such as the Pregnancy and Birth to 24 Months Project and the Scientific Report of the Dietary Guidelines Advisory Committee have provided significant contributions to addressing these gaps on key questions related to infant and toddler feeding. ${ }^{34,35}$ Specific guidance on food preparation methods, while limited, has been included in some fashion (ie, describing the developmental readiness for beginning to eat solid foods) in the US Dietary Guidelines for Americans 2020-2025. ${ }^{31}$ Continued efforts to provide evidenceinformed guidance for feeding infants and young children is 
important, and studies, such as the WIC ITFPS-2, can help researchers and public health practitioners advance the understanding of infant and young child feeding.

There are several strengths to this analysis. First, WIC ITFPS-2 is a longitudinal study among a low-income population with frequent data collection during a period of rapidly changing feeding practices and behaviors. Our analytic sample included only data on food preparation practices at 4-time points between 7 and 13 months, allowing us to identify these practices for the same group of mother-child dyads. Because we limited our analysis to those who answered all 4 surveys, our sample was more limited. However, no differences in sociodemographic characteristics were found between the study population and the analytic population at each respective survey month. Data were stratified by several sociodemographic factors providing insights into different feeding practices that can be explored in future research, including any contextual reasons why feeding practices were chosen and how these reasons might differ by stratifications such as race and ethnicity. There were also several limitations. Although these data are generalizable to the enrolled WIC population, they are only generalizable to WIC sites that enroll $\geq 30$ participants per month (37\% of WIC sites); however, sites with $\geq 30$ participants per month represent almost $90 \%$ of WIC participants. ${ }^{8}$ These data were collected beginning in 2013 and most likely span the period of 2013-2015 depending on when an infant was enrolled; however, food preparation practices could have changed since this time. This may be especially true with the coronavirus disease 2019 pandemic and shifts in the WIC program to adopt and allow for flexibilities in participating families $^{36}$ and other impacts such as a reduction in vaccinations and missed well-child visits. ${ }^{37,38}$ Food preparation practices were limited to 5 broad food categories for food prepared at home, and it is unknown how foods that were not included in these categories were prepared or how foods were prepared if they were all storebought baby foods. Dietary quality of foods was not accounted for, only how foods were prepared. Dietary quality differs by age, ${ }^{39}$ but assessing this was beyond the scope of this analysis. The proportion of caregivers using multiple feeding practices was not assessed, so the proportion of feeding practices that made up an individual infant's diet were not assessed. Finally, how foods were fed to the child could not be accounted for because these data were unavailable. For example, children at later ages may have been feeding themselves using a spoon for a puree or mashed foods, which supports the development of fine motor skills and increases feeding independence. ${ }^{16}$

\section{IMPLICATIONS FOR RESEARCH AND PRACTICE}

Among a cohort of infants enrolled in WIC, a variety of food preparation practices were used from 7 months to 13 months, consistent with recommendations appropriate for child development. Food preparation practices moved from pureed and mashed foods at 7 and 9 months into a higher proportion of chopped/diced foods by 13 months, with differences noted consistently by race and ethnicity. Exposing young children to a variety of textures early in life can support food acceptance. ${ }^{3}$ More research on food preparation practices, including prechewing and the contextual reasons for these preparation practice choices, is needed to understand the risks and benefits on child health. An example could include a factor analysis assessing each feeding practice and the different characteristics that explain that particular feeding method at different time points which could be useful to practitioners. Continued culturally relevant efforts by WIC educators, pediatricians, and other health care providers to emphasize the importance of early experiences with different food textures could help support the development of positive current and future dietary behaviors and practices.

\section{ACKNOWLEDGMENTS}

This project was supported in part by appointment to the Research Participation Program at the Centers for
Disease Control and Prevention administered by the Oak Ridge Institute for Science and Education through an interagency agreement between the US Department of Energy and the Centers for Disease Control and Prevention. The findings and conclusions in this report are those of the authors and do not necessarily represent the official position of the Centers for Disease Control and Prevention

\section{SUPPLEMENTARY DATA}

Supplementary data related to this article can be found at https://doi. org/10.1016/j.jneb.2021.08.006.

\section{REFERENCES}

1. Coulthard H, Harris G, Emmett P. Delayed introduction of lumpy foods to children during the complementary feeding period affects child's food acceptance and feeding at 7 years of age. Matern Child Nutr. 2009;5:75-85.

2. Harris G, Mason S. Are there sensitive periods for food acceptance in infancy? Curr Nutr Rep. 2017;6:190-196.

3. Harris G, Coulthard H. Early eating behaviours and food acceptance revisited: breastfeeding and introduction of complementary foods as predictive of food acceptance. Curr Obes Rep. 2016;5:113-120.

4. US Department of Agriculture. Infant Nutrition and Feeding: A Guide for Use in the Special Supplemental Nutrition Program for Women, Infants, and Children (WIC). USDA; 2019.

5. American Academy of Pediatrics Committee on Nutrition. Chapter 6. Complementary feeding. In: Kleinman RE, Greer FR, eds. Pediatric Nutrition, 7th ed., American Academy of Pediatrics; 2014.

6. National Academies of Sciences Engineering and Medicine. Feeding Infants and Children From Birth to 24 Months: Summarizing Existing Guidance. The National Academies Press; 2020.

7. US Department of Agriculture. WIC 2017 eligibility and coverage rates. https://www.fns.usda.gov/wic-2017eligibility-and-coverage-rates. Accessed January 13, 2021.

8. May L, Borger C, Weinfield N, et al. WIC Infant and Toddler Feeding Practices Study-2: infant year report. https://www. fns.usda.gov/wic/wic-infant-and-toddler- 
feeding-practices-study-2-infant-yearreport. Accessed March 5, 2021.

9. Pelto GH, Zhang Y, Habicht JP, Tolboom JJ, Lack G, Penagos M. Commentaries on premastication: the second arm of infant and young child feeding for health and survival? Matern Child Nutr. 2010;6:19-26.

10. Habicht JP, Pelto GH. Addressing epidemiological and public health analytic challenges in outcomes and impact research: a commentary on "prechewing infant food, consumption of sweets and dairy and not breastfeeding are associated with increased diarrhea risk of ten month old infants." Matern Child Nutr. 2016;12:625-631.

11. Rakhmanina N, Hader S, Denson A. Premastication of food by caregivers of HIV-exposed children-nine U.S. Sites, 2009-2010. MMWR Morb Mortal Wkly Rep. 2011;60:273-275.

12. Gaur A, Dominguez K, Kalish ML, et al. Practice of feeding premasticated food to infants: a potential risk factor for HIV transmission. Pediatrics. 2009;124:658-666.

13. Steinkuller JS, Chan K, Rinehouse SE. Prechewing of food by adults and streptococcal pharyngitis in infants. $J$ Pediatr. 1992;120:563-564.

14. Harrison R, Benton T, Everson-Stewart S, Weinstein P. Effect of motivational interviewing on rates of early childhood caries: a randomized trial. Pediatr Dent. 2007;29:16-22.

15. Pelto GH, Zhang Y, Habicht JP. Premastication: the second arm of infant and young child feeding for health and survival? Matern Child Nutr. 2010;6: 4-18.

16. Pérez-Escamilla R, Segura-Pérez S, Lott M, on behalf of the RWJF HER Expert Panel on Best Practices for Promoting Healthy Nutrition Feeding Patterns and Weight Status for Infants and Toddlers from Birth to 24 Months. Feeding Guidelines for Infants and Young Toddlers: A Responsive Parenting Approach. Healthy Eating Research; 2017.

17. Park S, Pan L, Sherry B, Li R. The association of sugar-sweetened beverage intake during infancy with sugar-sweetened beverage intake at 6 years of age. Pediatrics. 2014;134(suppl 1):S56-S62.

18. Grimm KA, Kim SA, Yaroch AL, Scanlon KS. Fruit and vegetable intake during infancy and early childhood. Pediatrics. 2014;134(suppl 1):63-69.

19. Northstone K, Emmett P, Nethersole F, ALSPAC Study Team. Avon longitudinal study of pregnancy childhood. The effect of age of introduction to lumpy solids on foods eaten and reported feeding difficulties at 6 and 15 months. J Hum Nutr Diet. 2001;14:4354.

20. Rose CM, Birch LL, Savage JS. Dietary patterns in infancy are associated with child diet and weight outcomes at 6 years. Int J Obes (Lond). 2017;41:783-788.

21. Northstone K, Emmett P. The associations between feeding difficulties and behaviours and dietary patterns at 2 years of age: the ALSPAC cohort. Matern Child Nutr. 2013;9:533-542.

22. Pan L, Li R, Park S, Galuska DA, Sherry B, Freedman DS. A longitudinal analysis of sugar-sweetened beverage intake in infancy and obesity at 6 years. Pediatrics. 2014;134(suppl 1):S29-S35.

23. Blossfield I, Collins A, Kiely M, Delahunty C. Texture preferences of 12month old infants and the role of early experiences. Food Qual Preferences. 2007;18:369-404.

24. Paroche MM, Caton SJ, Vereijken CMJL, Weenen H, Houston-Price C. How infants and young children learn about food: a systematic review. Front Psychol. 2017;8:1046.

25. Hamner HC, Paolicelli C, Casavale KO, Haake M, Bartholomew A. Food and beverage intake from 12 to 23 months by WIC status. Pediatrics. 2019;143:e20182274.

26. Tester JM, Leung CW, Crawford PB. Revised WIC food package and children's diet quality. Pediatrics. 2016;137: e20153557.

27. American Academy of Pediatrics, Institute for Healthy Childhood Weight. Building a foundation for healthy active living. Educating and engaging parents and families. https://ihcw.aap.org/Pages/EFHALF_parents.aspx. Accessed January 12, 2021.

28. American Academy of Pediatrics, Institute for Healthy Childhood Weight. Building a foundation for healthy active living: finger foods poster. https:// ihcw.aap.org/resources/Documents/ fingerfoodsposterfinalv01.pdf. Accessed January 12, 2021.

29. National WIC Association. WIC \& health resources for Native Peoples. https://www.nwica.org/blog/indigenous-alaskan-native-american-indianwic-resource-page\#.YP7JnLqSm70. Accessed July 12, 2021.

30. Diaz-Rios LK, Muzaffar H, Meline B, Chapman-Novakofski K. Talk, Heart,
Hands: a culturally sensitive approach to nutrition education for Latinos with young children. J Nutr Educ Behav. 2016;48:425-429.

31. US Department of Agriculture, US Department of Health and Human Services. Dietary Guidelines for Americans 2020-2025. USDA; 2020. https:// www.dietaryguidelines.gov/resources/ 2020-2025-dietary-guidelines-onlinematerials. Accessed July 15, 2021.

32. Fialkowski MK, Fonesca-Smith T, Pinto PEK, Ng-Osorio J. Native Hawaiian complementary feeding practices as told by grandparents: a transgenerational experience. Curr Dev Nutr. 2021;5(suppl 4):40-53.

33. Montieth H, Galloway T, Hanley AJ. Protocol for a scoping review of the qualitative literature on Indigenous infant feeding experiences. BMJ Open. 2020;11:e043476.

34. Stoody EE, Spahn JM, Casavale KO. The Pregnancy and Birth to 24 months Project: a series of systematic review on diet and health. Am J Clin Nutr. 2019;109(suppl):685S-697S.

35. Dietary Guidelines Advisory Committee. Scientific Report of the 2020 Dietary Guidelines Advisory Committee: Advisory Report to the Secretary of Agriculture and the Secretary of Health and Human Services. US Department of Agriculture, Agriculture Research Service; 2020.

36. US Department of Agriculture, Food and Nutrition Service. FNS responds to COVID-19. https://www.fns.usda.gov/ coronavirus. Accessed July 13, 2021.

37. Santoli JM, Lindley MC, DeSilva MB, et al. Effects of the COVID-19 pandemic on routine pediatric vaccine ordering and administration - United States, 2020. MMWR Morb Mortal Wkly Rep. 2020;69:591-593.

38. Centers for Disease Control and Prevention. Catch-up on well-child visits and recommended vaccinations. https:// www.cdc.gov/vaccines/parents/visit/ vaccination-during-COVID-19.html. Accessed July 13, 2021.

39. Hamner HC, Moore LV. Dietary quality among children from 6 month to 4 years, NHANES 2011-2016. Am J Clin Nutr. 2020;111:61-69.

\section{ORCID}

Heather C. Hamner: http://orcid.org/ 0000-0003-1590-6254 